\title{
„STORYTELLING“ KAO NAČIN PREZENTACIJE KULTURNOG NASLEĐA U KONTEKSTU TURISTIČKOG VOĐENJA
}

\section{Jelena Stajčić ${ }^{1}$ Olgica Živković}

${ }^{1}$ Turistička agencija „TCA travel agency", Beograd Srbija

${ }^{2}$ Licencirani turistički vodič
Correspondence:

Jelena Stajčić

e-mail:

jelena.stajcic.10@singimail.rs

\section{Rezime:}

Uveliko je prevaziđen koncept 3S: sunce, pesak, more. Pogotovu to važi za zemlje koje su bazirane na razvoj receptivnog turizma, stavljajući akcenat na kulturno-istorijsko nasleđe. U poslednje dve decenije, rastući trend u svetu je pripovedanje, dok je u Srbiji još uvek u početnoj fazi. Danas se pripovedanje može smatrati kao moćnim ko-kreativnim ponašanjem u turizmu. Iz tog razloga, primarni cilj ovog istraživanja jeste da analizira dosadašnje efekte korišćenja priča u prezentaciji kulturnog nasleđa prilikom vođenja. Ovaj članak će se usredsrediti na razvoj jednog kreativnog projekta u kulturnom turizmu koji izvodi licencirani turistički vodič. Detaljno ćemo objasniti specijalizovane ture sa predmetom istraživanja i kako se tumači i približava turistima veliko nasleđe koje baštinimo u vezi sa Nikolom Teslom. Čitav projekat je nastao u okviru kulturne rute „Putevima Tesle“. Konkretan projekat specijalizovanih Tesla tura uporedićemo sa turom u prvom licu koje se realizuje u konaku knjeginje Ljubice.

Ključne reči:

pripovedanje, turistički vodič, kulturno nasleđe, kulturni turizam

UVOD

Turizam se već odavno ne bazira na suncu i moru. Shodno postojećim trendovima u proteklim decenijama, danas više nego ikada, fokus je na doživljaju, emocijama i priči. Ako se u ovoj privrednoj grani radi prvenstveno o prodaji iskustva, pričanje priča dobija posebno na važnosti. Rezultati istraživanja pokazali su kako storytelling kao marketinški alat u savremenom turizmu ima ogromnu snagu iz koje mogu proizaći brojni benefiti i za destinaciju i za posetioce. Izvori iz kojih se crpe teme za pripovedanje su brojni i zapravo sami atraktivni elementi koji čine srž jedne turističke destinacije, kao što su poznate istorijske ličnosti, hrana, priroda, kulturno-istorijski spomenici i tradicija mogu da se upotrebe kao baza oko kojih se plete priča. Priprema jedne takve tematske ture iziskuje podrobno istraživanje, dok drugi deo predstavlja realizacija, gde vodiči-interpretatori koji bi trebalo da se sažive sa događajem ili ličnošću koje tumače, koriste i glumačku tehniku kako bi tokom vođenja privukli i zadržali pažnju prisutnih na turi, a potom ih i motivisali da sami prošire stečeno znanje i otkriju šta može da im još pruži mesto u kojem borave. 


\section{ŠTA JE STORYTELLING?}

Ako se zapitamo šta je storytelling, na engleskom dobijamo objašnjenje da je to društvena i kulturna aktivnost prikupljanja i deljenja priča, gde se često javlja potreba za improvizacijom, teatarskim elementima i ukrašavanjem. U našem jeziku, najpribližniji pojam navedenom bi bio „pripovedanje“. Prema Miller-u (http:// www.zarez.hr/clanci/definicija-pripovijedanja) reč „tell“ koja je sastavni deo izraza „storytelling“ je višeznačna i može da se odnosi doslovno na korišćenje govora kako bi se nešto verbalno iskazalo, ali i na izražavanje na bilo koji drugi način, uključujući vizuelni ( $a$ telling glance - pogled koji govori), na opšte odvijanje stvarnosti (time will tell - vreme će pokazati), a može se odnositi i na samu percepciju (I can tell - vidim). Stoga „tell“ predstavlja sinestezijski izraz koji obuhvata potpuno uranjanje u iskustvo. Dalje autor navodi da se ovaj pojam upotrebljava za nastup pripovedača u kojem on neposredno pred publikom iznosi određeni tok događaja.

U turizmu storytelling se javlja 90-ih godina, u turističkom smislu kao stvaranje "nezaboravnih iskustava" (Pizam, 2010), te je predložen kao rešenje problema kako inspirisati i zabaviti turiste (Moscardo, 2010; Bedford, 2001). Storytelling koncept prema Mosbergu $(2008,196)$ stimuliše našu maštu, uključuje nas emotivno i zabavlja. Vremenom, uvidelo se da turista ne želi da bude izložen jednosmernoj priči, već da tokom ture bude „uvučen“ u priču i oseti da i on sam aktivno učestvuje. Koristi se kao način animacije turista u turističkim destinacijama i muzejima razvijajući veštine slušanja i razumevanja raznovrsnih istorijskih činjenica, kroz slikovite priče o životima običnih ljudi. Storytelling povećava vrednost destinacije putem stimulisanja turističkih aktivnosti i tako širi novu vrednost na osnovu razvijenog individualnog iskustvenog procesa u vezi sa pričom o turističkoj atrakciji (Soon Choi, 2016). Priča se razvija tokom vremena i ima različite delove, kao što je početak u kome su predstavljeni likovi, sredina sa tačkom bez povratka, a zatim i treći čin, sa završetkom priče i povratkom u običan svet (Mossberg, 2008). Vodič deluje kao pomoćnik i održava delove priče zajedno. Prvo, turistički vodiči su posrednici između objekata nasleđa i turista i kao takvi kreatori utisaka objekata nasleđa. Drugo, vodiči koji mogu da uključe tehniku pripovedanja pri njihovom tumačenju su efikasniji u smislu stvaranja većeg utiska za tumačene objekte. Potrebno je samo ispričati dobru priču.

\section{PRIMER IZ PRAKSE MUZEJA GRADA BEOGRADA}

Prvi Storytelling koji je zaživeo na području Beograda jeste „Na kafi kod knjeginje Ljubice“ u okviru programa Muzeja grada Beograda. Nataša Popovska, istoričar umetnosti i viši kustos, svoj autorski tekst uz podršku Turističke organizacije Beograda, pretočila je u posebnu turu koja je uvrštena u redovni program Konaka knjeginje Ljubice. Realizacija ture započela je 2009. godine, prvo na srpskom, a potom od 2011. godine i na engleskom jeziku. Posetioci su do skoro imali priliku da vide kako kostimirana kustoskinja u prvom licu dočarava život u Beogradu iz vremena dinastije Obrenović. Tokom ture, deo programa je podrazumevao da svi prisutni budu posluženi kafom i domaćim ratlukom, što je još više doprinosilo utisku povezanosti sa likom knjeginje Ljubice, odnosno vodičem i stvaralo svojevrsnu atmosferu prisnosti i osećaja izmeštenosti iz sadašnjeg vremena u 19. vek. Na neki način, zaslugom vodiča-tumača, stvarao se osećaj da sedite sa prijateljicom koja vam poverava lične stvari iz svog komplikovanog života i vi imate potrebu da pažljivo slušate kako biste je posavetovali i pomogli. Ta emocija koja je izazvana u vama, znači samo jedno, da ste već duboko upleteni u priču, a sledeći logičan korak je da ćete se još više potruditi da saznate o ličnostima i događajima koje ste čuli, kada se tura završi. Što je uostalom i krajnji cilj pripovedanja u turizmu, da sami krenuti u istraživanje o temi jer vas je sve to duboko zaintrigiralo.

U tabeli ispod je dat prikaz realizovanih tura „Na kafi kod knjeginje Ljubice“, kao i broj domaćih i stranih posetilaca u proteklom periodu na godišnjem nivou. Od 2009. zaključno sa 2013. godinom, nije vođena godišnja statistika, već su prikazani zbirni podaci. Iz priloženog vidi se da je najveći broj turista bilo 2016. godine, ukupno 2 216, u isto vreme je oboren rekord što se tiče turista sa stranih govornih područja (413), dok je 2014. godina bila u znaku dominacije domaćeg turizma (2 099). Jeste da statistika nepobitno pokazuje da se u poslednjih par godina smanjuje interesovanje, ali treba napomenuti da se program izvodio i van zgrade muzeja, u osnovnim i srednjim školama, na manifestacijama, u okviru proslave jubileja pojedinih državnih institucija i firmi, ali ništa od toga nije zavedeno. Pošto su uzeta samo dva elementa prilikom beleženja posete, domaći 
i strani turisti, nije moguće precizno doneti zaključke o razlozima opadanja brojnosti posetilaca opisanom muzejskom programu. Da je od strane muzeja sprovedena neka anketa koja uključuje pitanja o starosnoj dobi, obrazovanju, mestu boravka i ličnim interesovanjima, onda bi već moglo da se pristupi ozbiljnijoj statističkoj analizi i da se sa većom sigurnošću kaže zašto dolazi do stagnacije i opadanja. Usled privatnih obaveza autorke, tura se neće realizovati do maja naredne godine, tako da je razumljivo što je bilo svega 26 izvođenja do sada.

Tabela 1. Tura "Na kafi kod knjeginje Ljubice"

\begin{tabular}{ccccccc}
\hline Period & $\begin{array}{c}\text { Ukupan } \\
\text { broj tura }\end{array}$ & $\begin{array}{c}\text { Ture na } \\
\text { engleskom } \\
\text { jeziku }\end{array}$ & $\begin{array}{c}\text { Turena } \\
\text { srpskom } \\
\text { jeziku }\end{array}$ & $\begin{array}{c}\text { Ukupan broj } \\
\text { posetilaca }\end{array}$ & $\begin{array}{c}\text { Broj stranih } \\
\text { turista }\end{array}$ & $\begin{array}{c}\text { Broj domaćih } \\
\text { turista }\end{array}$ \\
\hline $\begin{array}{c}\mathbf{3 . 1 0 . 2 0 0 9 .} \\
\mathbf{2 1 . 1 2 . 2 0 1 3 .}\end{array}$ & 301 & 53 & 248 & 8516 & 1092 & 7424 \\
\hline $\mathbf{2 0 1 4 .}$ & 97 & 11 & 86 & 2330 & 231 & 2099 \\
\hline $\mathbf{2 0 1 5 .}$ & 112 & 15 & 97 & 2216 & 413 & 1803 \\
\hline $\mathbf{2 0 1 6 .}$ & 112 & 11 & 101 & 2119 & 203 & 1916 \\
\hline $\mathbf{2 0 1 7 .}$ & 98 & 9 & 89 & 1833 & 132 & 1701 \\
\hline do 5.05.2018. & 26 & 1 & 25 & 475 & 9 & 466 \\
\hline
\end{tabular}

Izvor: Obrada autora prema podacima koje je ustupila kustoskinja Dragana Latinčić (Muzej grada Beograda)

\section{PRIPOVEDAČKE TURE O NIKOLI TESLI - PRIMER}

Naredni primer preuzet je iz prakse jednog od autora ovog rada i prikazuje na koji način može da se promoviše i unapređuje kulturno nasleđe koje baštinimo o Nikoli Tesli kroz pripovedačku formu. Različite varijacije tura o Tesli nastale su namenski za program manifestacije "Tesla dani” koja se realizuje od 2014. godine u mesecu julu, kada se obeležava rođendan poznatog naučnika. Zapravo, Manuela Graf (http://teslaways.rs/), menadžer organizacije „Klaster puteva kulture“, koja je i ustanovila kulturnu rutu „Tesla ways“ je ponudila jednoj od autorki rada da osmisli i pripremi jednu tematsku turu o Tesli, Iako su ture izvođene u različitom okruženju koje je diktiralo glavnu temu, kroz svaku od tura provlači se priča o Teslinoj poseti Beogradu iz 1892. godine, kada je tom prilikom proveo svega 31 sat u srpskoj prestonici i ostavio neizbrisiv trag. Autorka ture je kostimirana i zapravo je zamisao da se javi u ulozi "duha Teslinog vremena", vodeći posetioce na svojevrsno putovanje kroz Teslin život. Nižu se slike od rođenja u malom mestu Smiljanu u Lici, tada u okviru Austrougarskog carstva, preko školovanja Nikolinog u Gracu i Pragu, do prvih poslova koje je obavljao u Mariboru i Budimpešti. Obavezno se spominju i najznačajniji pronalasci naučnika, kao što je obrtno magnetno polje, radio signal, naizmenične struje visokih frekvencija i rad na bežičnom prenosu energije. Sve ture do sada su pokrivene medijski, tako da je dostupan štampani i video materijal.

Vremenom došlo se do zaključka da su dve najatraktivnije varijante ove ture "Obilazak stogodišnjih kabineta ETF-u“, koja se realizuje na Elektrotehničkom fakultetu i tom prilikom se obilaze kabineti gde se još uvek nalaze stari generatori, otpornici i drugi aparati koji su stari oko 100 godina, ali i dalje su u funkciji. Čitava oprema dobijena je putem ratne reparacije. Naime, nakon završetka II svetskog rata, Nemačka je poslala aparaturu za fakultetsku laboratoriju koja je proizvedena u njihovoj firmi "Simens \& Halske“, koja je svojevremeno čak tražila da otkupi opremu od fakulteta da bi je predstavila kao muzejske eksponate u okviru izložbe o svom industrijskog nasleđu. Međutim, tadašnji dekan prof. Branko Kovačević s pravom i na svu sreću, nije želeo da je otuđi. Kao prostor za drugu turu "Kraljevski doček za Nikolu Teslu" poslužili su saloni Skupštine grada Beograda. Tom prilikom rekonstruišu se događaji koji su doveli do gradnje Starog dvora, a kreću od kupovine placa u močvarnom delu Terazija od prvog vlasnika Stojana Simića, bogatog trgovca, političara i ustavobranitelja, koji posle uređenja parcele po znatno višoj ceni prodaje svojinu knezu Aleksandru Karađorđeviću. Potom dolazi do smene kraljevske porodice gde na vlast dolaze Obrenovići. Konačno, tokom ture prolazeći kroz crveni i žuti salon dolazi se i do balske dvorane koja je delimično rekonstruisana iz perioda 
poslednjeg vladara Obrenovića, mladog kralja Aleksandra koji je i dočekao Teslu u dvoru kada je naučnik boravio u Beogradu. Posebno vlada velika zainteresovanost za ovu turu jer to jedinstvena prilika da se prođe kroz unutrašnjost Skupštine grada, koja predstavlja jedno od naših najreprezentativnijih zdanja. Tada posetioci mogu da vide neprocenjiva umetnička dela naših slikara, Šumanovića, Lubarde, Milosavljevića, Omčikusa, a takođe im je dostupan faksimil pisma pape Jovana VIII od 16. aprila 878. godine, dokument u kojem se po prvi put spominje slovensko ime naše prestonice.

Autorka nije vodila preciznu statistiku o broju posetilaca svaki put. Ipak poznato je da je 2016. godine u mesecu julu na četiri organizovane ture u Starom dvoru bilo prisutno 350 domaćih turista. Na veliku posećenost je uticalo više faktora, pre svega atraktivnost samog prostora, kao i kostimiranost vodiča i sam princip pripovedanja. Starosna dob posetilaca je vrlo šarenolika, od osnovaca do osoba u zrelim godinama. Isto tako je dijapazon širok što se tiče stručnosti, posetioci su bili od onih koji nemaju nikakvih dodirnih tačaka sa prirodnim naukama, do onih koji su završili neki od tehničkih fakulteta, ali bez obzira na tu činjenicu svi su mogli da prate priču.

Slika 1. Tura "Kraljevski doček za Nikolu Teslu"

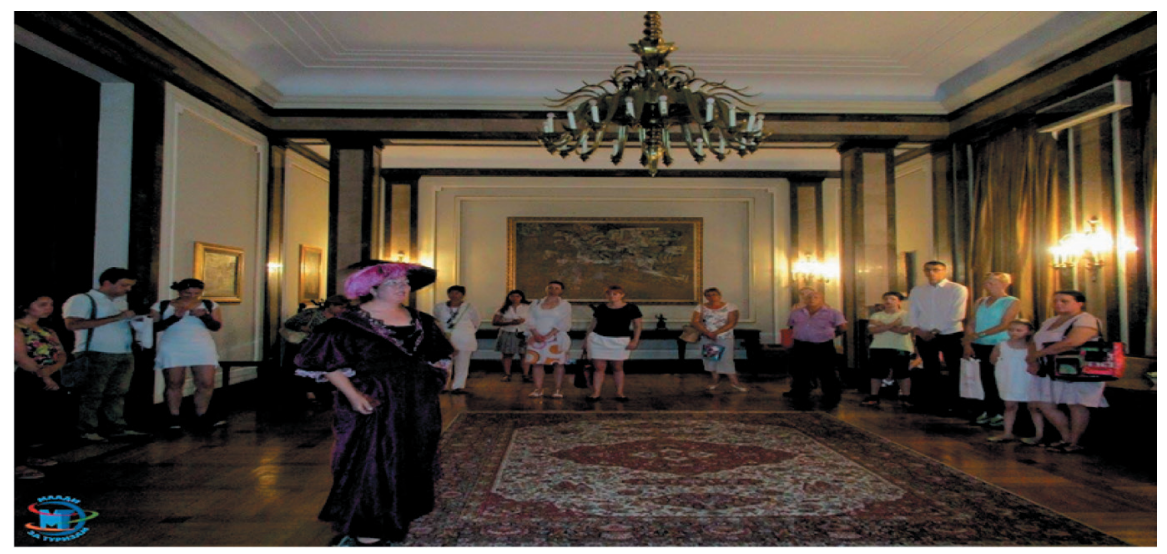

Izvor: Privatna arhiva autora

\section{ZAKLJUČAK}

Cilj ovog rada je da pomogne turističkim vodičima i tumačima nasleđa razumevanjem da li, kako i zašto uključiti pričanje u svakodnevnom radu. Storytelling se pokazao kao idealna strategija za motivisanje slušalaca, jer dobro osmišljena priča se lakše pamti, a samim tim motiviše turiste da istražuju dalje sami o predmetu interesovanja, koji čini siže ture. Uostalom, svi su kao deca imali priliku da slušaju bajke koje na prijemčiv način govore o večitoj temi borbe dobra i zla. Tako da pripovedanje predstavlja moćan alat u turizmu koji turistu vraća u detinjstvo, u svet priča gde je sve moguće i tom prilikom ako interpretator probudi kod slušaoca pozitivnu emociju, u ovom slučaju dolazi do čvrste veze između turističke destinacije i turiste koja može da rezultira ponovnim vraćanjem u isto mesto i prenošenjem doživljenog, putem marketinga „od usta do usta“ svojim prijateljima, što na duže staze, dovodi do povećanja vidljivosti same destinacije i posredno, turističkog prometa. Svakako, pripovedanje u budućnosti, kada se još razvije u Srbiji, sigurno će poslužiti kao inicijalna kapisla i spasonosno rešenje, za oživljavanje pojedinih turističkih destinacija, kada u svom normalnom životnom ciklusu dosegnu do pozicije stagnacije pa i samog gašenja.

Iz razgovora sa zaposlenima u Muzeju grada Beograda, nameće se zaključak da je ovakav tip ture doprineo stvaranju nove slike o Konaku knjeginje Ljubice, povećao broj redovnih posetilaca muzeja i stvorio preko potrebnu interakciju. Takođe, to je podstaklo druge kustose da stave akcenat na veće uključivanje publike u buduće programe. Tako su nastale brojne radionice za decu, kao na primer: „Mozaik“, gde se osnovci upoznaju sa tehnikom izrade mozaika, „Glagoljenje“, radionica na kojoj uče slova glagoljice, dobijaju šira saznanja o našem pismu ćirilici i uče o prosvetiteljskoj ulozi Vuka Karadžića i Dositeja Obradovića. Poredeći dva data 
primera, treba napomenuti da je tura "Na kafi kod knjeginje Ljubice" komercijalna, dok su sve ture o Tesli koje su realizovane u okviru drugih manifestacija, bile besplatne. Moguće da je i taj momenat doprineo da veliki broj turista prisustvuje turi o Tesli, jer nisu morali da izdvoje novac. Naravno, obe ture su doprinele, svaka u svom domenu, zahvaljujući korišćenu koncepta Storytellinga da se promovišu posete Konaku knjeginje Ljubice i manifestaciji “Tesla dani”. Svakako postoji zainteresovanost za ovakav tip tura kod nas, ali činjenica je da još nisu u potpunosti zaživele.

\section{LITERATURA}

Bedford, L. (2001). Storytelling: the real work of museums. Curator: The Museum Journal, 44(1), 27-34.

Graf, M. (2014). Putevima Tesle/Tesla ways. Preuzeto 20. oktobra 2018. sa: http://www.teslaways.rs/index.php

Miller, E. (2008, Maj). Definicija pripovedanja. Preuzeto 1. novembra 2018. sa: http://www.zarez.hr/clanci/ definicija-pripovijedanja

Moscardo, G. M. (2010). The shaping of tourist experience. The importance of stories and themes. In M. Morgan, P. Lugosi, \& J. R. B. Ritchie (Eds.), The tourism and leisure experience. Consumer and managerial perspectives (pp. 43-58). Bristol, UK: Channel View Publications

Mossberg, L. (2008). Extraordinary Experiences through Storytelling. Scandinavian Journal of Hospitality and Tourism, 8(3), 195-210. DOI:10.1080/15022250802532443

Pizam, A. (2010). Creating memorable experiences. International Journal of Hospitality Management, 29(3), 343.

Soon Choi, S. (2016). A Study on Effect of Tourism Storytelling of Tourism Destination Brand Value and Tourist Behavioral Intentions. Indian Journal of Science and Technology, 9(46), 5-6. DOI:10.17485/ijst/2016/ v9i46/107387

\section{STORYTELLING AS A WAY OF PRESENTING CULTURAL HERITAGE IN THE CONTEXT OF TOURISM GUIDANCE}

\begin{abstract}
: Residence of Ljubica.

Keywords:

storytelling, tour guide, cultural heritage, cultural tourism
\end{abstract}

Concept 3S: sun, sand, sea it's been overcome long ago. Especially for countries that are based on the development of receptive tourism, putting emphasis on cultural and historical heritage. In the last two decades, the growing trend in the world is storytelling, while in Serbia it is still in the initial phase. Today storytelling can be considered as a powerful co-creative behavior in tourism. For this reason, the primary aim of this study is to analyze the current effects of using stories in the presentation of cultural heritage while conducting. This article will focus on the development of a creative cultural tourism project run by a licensed travel guide. We will explain in detail the specialized tours with the subject of the research and how to interpret and approach the immense heritage that we inherit in relation to Tesla. The whole project was created within the cultural route «Tesla ways». A concrete project of specialized Tesla tours will be compared with the first-person tour that is being realized in The 